\title{
LOCAL INNOVATION IN A GLOBAL CONTEXT: DOCUMENTING FARMER INITIATIVES IN LAND HUSBANDRY THROUGH WOCAT
}

\author{
W. R. S. CRITCHLEY ${ }^{1} *$ AND K. MUTUNGA $^{2}$ \\ ${ }^{1}$ Vrije Universiteit, Amsterdam, The Netherlands \\ ${ }^{2}$ Ministry of Agriculture and Rural Development, Nairobi, Kenya \\ Received 9 January 2002; Revised 5 April 2002; Accepted 29 August 2002
}

\begin{abstract}
Innovation by farmers in land husbandry was the focus of the project Promoting Farmer Innovation (PFI), which was operational in Kenya, Tanzania and Uganda from 1997 to 2001. One of the project's final activities was to document best-bet innovations. It was decided to make use of a questionnaire available under the World Overview of Conservation Approaches and Technologies (WOCAT) to collect data on a selection of these technologies. Data were fed back into WOCAT's global database. Eighteen technical initiatives were recorded in this way, and the findings added to existing data and in-house knowledge. This information was analysed and a technical report produced (Mutunga and Critchley, 2001). The technologies included turning gullies into gardens, digging planting pits for millet and sorghum and harvesting water from roads. Each combined aspects of land conservation with improved plant production. While several required relatively high initial labour input, all were considered economically beneficial by the farmers. Adoption by other farmers was generally rapid, partially as a result of farmer to farmer visits under PFI. The value of the PFI-WOCAT exercise was not restricted to recording and disseminating information, however. It was also a test of the utility of WOCAT within a project. There were a number of interesting findings. Although those who filled the questionnaires found it an onerous task, they felt that they learned a good deal as they went through the process. One of the main conclusions was that the questionnaire could be a very valuable template to help guide internal monitoring and evaluation, if used from the start of a project intervention. Copyright (C) 2002 John Wiley \& Sons, Ltd.
\end{abstract}

KEY WORDS: soil and water conservation; land husbandry; indigenous knowledge; farmer innovation; World Overview of Conservation Approaches and Technologies (WOCAT); East Africa

\section{INTRODUCTION}

Promoting Farmer Innovation (PFI) was both the name and the key activity of a project in East Africa which ended in 2001. The methodology and early results of PFI have already been introduced in various publications (Critchley et al., 1999a; Critchley, 2000). Briefly, PFI sought to use local farmer innovation in the field of land husbandry as a stimulus to more appropriate research and extension systems in semiarid and marginal areas. Towards the end of the project it was decided to document selected innovations. A methodology for description was available under the World Overview of Conservation Approaches and Technologies (WOCAT). The WOCAT had developed templates, in the form of questionnaires, to describe both technologies ('questionnaire technologies' or 'QT') and approaches ('questionnaire approaches' or 'QA') in the field of soil and water conservation (WOCAT, 1999a,b). These had not yet been tested in the context of an individual project. Thus there was an opportunity to make use of, and simultaneously test, WOCAT tools. Eighteen best-bet ${ }^{1}$ technical innovations/

\footnotetext{
*Correspondence to: W. R. S. Critchley, CDCS, International Cooperation Centre, De Boelelaan 1105, 1081 HV Amsterdam, The Netherlands. E-mail: f.nacion@dienst.vu.nl

${ }^{1}$ 'Best-bet' is used here to describe technologies which, according to the judgement and experience of project staff, had the best combination of effectiveness and adoptability. However, none had been thoroughly validated, and improvements would have be made to many.
} 
initiatives $^{2}$ were selected for description. The methodology and detailed results of this PFI-WOCAT exercise have been covered in full in a technical report (Mutunga and Critchley, 2001). Its aim was to introduce technicians and managers of projects (as well as literate farmers) to a range of potential alternative practices for the drier areas in the region. This paper is based on that booklet. While it focuses mainly on the approaches of PFI and WOCAT and the lessons of attempting to merge the two in a specific context, it also presents six case studies of innovators and their innovations to demonstrate examples of functional end product from such an exercise.

\section{BACKGROUND}

\section{Farmer Innovation and PFI}

Farmer innovation has been, historically, the means through which technological advances have been made and traditions developed (Richards, 1985; Chambers et al., 1989; Gupta, 1998). This process, however, has been masked by the emergence of a more structured, scientific paradigm involving researchers and extension agents, termed the 'transfer of technology' approach. While the latter flourished in the higher potential parts of the tropics in the 1960s and 1970s, it has largely failed the small-scale farmers of drought prone subSaharan Africa (Chambers et al., 1989; Reij and Waters-Bayer, 2001). Nowhere is this truer than in the field of soil and water conservation or land husbandry. The often-quoted environmental revival story of Machakos District in Eastern Kenya (usually referred to simply by the book's catchy title More People, Less Erosion, Tiffen et al., 1994) owes more to the innovativeness of the people under land pressure than technical guidance from outside. Currently there is growing attention being paid to the importance of indigenous of soil and water conservation (ISWC) (Critchley et al., 1994; Hurni et al., 1996; Reij et al., 1996). But attention must not begin and end with merely recognizing and admiring ISWC. The crucial question is: How can ISWC be harnessed constructively? In the specific context of farmer innovators we are asking: Can farmer innovation be stimulated to provide a source of adoptable technologies? and: Can farmer innovators constitute a useful means of helping to disseminate these ideas? If we believe the answer to be 'yes' to these last two questions, then we must find a way of translating this concept into practice.

Promoting Farmer Innovation has followed the process approach of learning by doing. From the beginning it was clear that PFI would take its lead from the participatory group of approaches. These include participatory learning and action (Pretty et al., 1995), participatory technology development (Van Veldhuizen et al., 1997), participatory monitoring and evaluation (Guijt, 1998) and participatory extension (Scarborough et al., 1997). But none of these covers the whole, and neither are these approaches strong in institutionalisation which must be a key element of a farmer innovation programme. Reij and Waters-Bayer (2001a) outline 10 'components' of a farmer innovation methodology. Under PFI these components, plus others, were shaped into a functional approach that varied little across the three countries. The methodology that gradually took shape can be conceptualised in the two diagrams (Critchley et al., 1999a). ${ }^{3}$ These shown in Figures 1 and 2 represent, respectively, what is done at the programme level (towards 'vertical scaling up' or institutionalization: Gündel et al., 2001) and what is done in the field (leading towards 'horizontal scaling up' or spread: Gündel et al., 2001). It is important in the context of this PFI-WOCAT exercise to draw attention to one particular field activity. That is step 3 'Characterization and analysis of farmer innovators and innovations'. Under that step, PFI had already compiled certain information. The PFI-WOCAT exercise was intended to supplement this.

The first phase of PFI closed officially at the beginning of 2001 with both tangible and methodological achievements (UNSO-UNDP, 2001). Experience has confirmed that there is indeed a considerable wealth of local farmer innovation in land husbandry. Analysis shows that innovative farmers gain inspiration typically from a mix of what they have seen outside their home areas and from their own creative ideas. They are characterized by being (often) middle-aged, and having an important livelihood stake in the land. Farmer innovators tend to be

\footnotetext{
${ }^{2}$ Note we use both the words 'innovations' and 'initiatives' in the title and the text. While the term 'innovations' has been used widely under the PFI project, many of the technologies are only innovations in local terms. The two words are used interchangeably here.

${ }^{3}$ As part of this PFI-WOCAT exercise, PFI's methodology (in Kenya specifically) has been described under WOCAT, through the 'Questionnaire Approaches' (QA).
} 


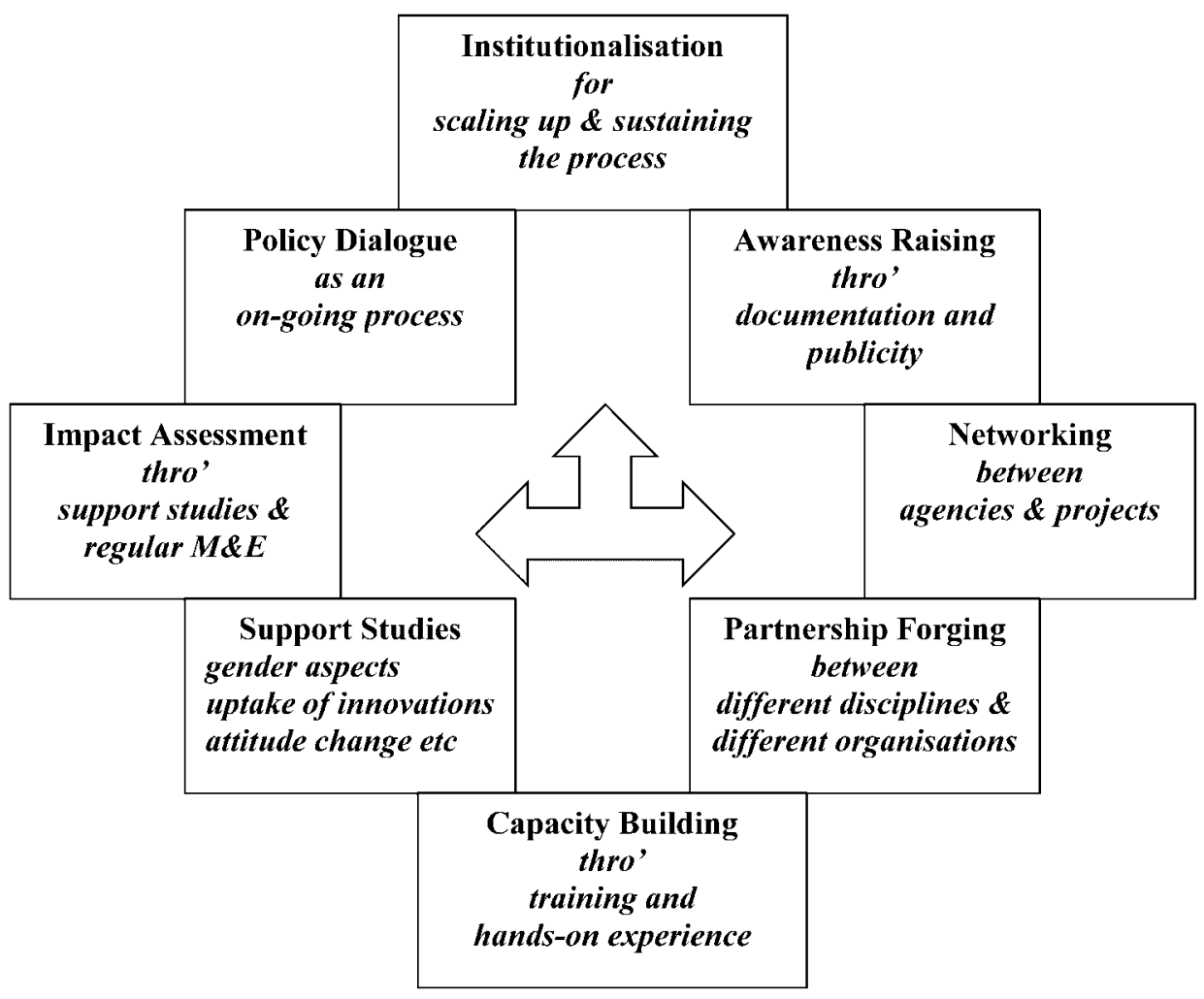

Figure 1. Programme development processes. Source: Critchley et al., 1999a.

imaginative, and demonstrate pride in their achievements when these are recognized. They apparently visualize patterns of integrating resources and intensifying production that escape others (Critchley et al., 1999a).

From the outset it was acknowledged that there are limitations to the farmer-innovation approach. These include the need to develop radically new roles for researchers and extensionists to stimulate and support tradition and innovation. Indigenous knowledge and innovation is clearly not enough if left on its own (Blaikie and Brookfield, 1987). Furthermore, innovations need to be assessed (validated), and often improved (value added) before being disseminated. There is also the danger of some innovators being so eccentric that they repel more ordinary neighbours: thus the need to be careful in identification of suitable innovator role models. Associated with this problem is the fact that too much attention to innovators may create a 'favoured-farmer syndrome' thus inciting jealousy. Many projects are curiously blind to this danger. Some innovations are very high-input 'labours of love' rather than being economically attractive to others (Critchley and Mosenene, 1996). Furthermore, innovativeness is not equally spread among communities - though it tends to be present everywhere, even among the poorest (Chambers et al., 1989; Nielson, 2001).

Experience has also helped pinpoint several further issues (Critchley, 2000). One is the definition of innovators and innovation. There simply must be a clear and stated understanding, though this may differ from country to country, or project to project. Under PFI the contextual definition of a 'farmer innovator' is someone who, in local terms at least, has developed/is testing new methods of land husbandry ('innovations') that combine production with conservation. A second issue involves monitoring and evaluation and impact assessment. There is a very real need for participatory programmes to stop shying away from quantitative as well as qualitative monitoring and evaluation. This is not just to satisfy the demands of the funding agencies, but for enhanced internal learning also. The WOCAT clearly could have an important role to play in these aspects (in the context of programmes that focus 


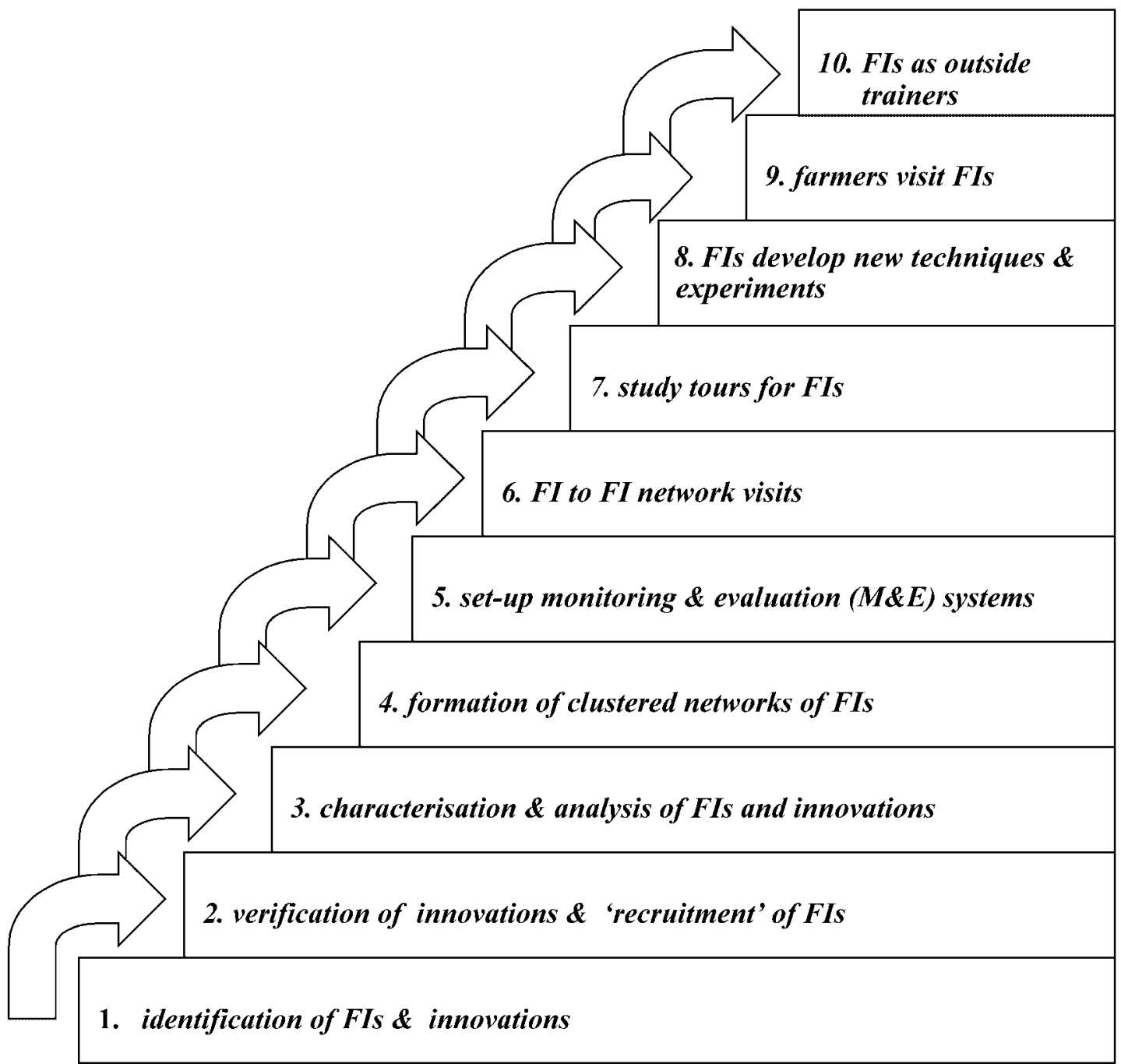

Figure 2. Field activities ten steps in harnessing farmer innovation. FIs = Farmer innovators; M\&E = Monitoring and evaluation. Source: Critchley et al., 1999a.

on soil and water conservation). Thirdly, a defined policy towards gender mainstreaming will often be important to make sure that both sexes are adequately represented in a programme. A fourth issue is intellectual property rights. Are we sharing or stealing? While water harvesting or soil conservation technologies are hardly likely to become marketable products in the way that indigenous medicinal remedies can be, there remains a question of intellectual 'ownership' and more simply, giving names to the technologies. Fifthly, there is cost-effectiveness, to which there are two subissues. The first is whether the individual innovation is a cost-effective measure. The second concerns the programme intervention itself: we must not establish a methodology that is potent, but too costly to justify expansion. The sixth issue is that of institutionalization. Enclave projects with lavish funding, a narrow focus in terms of area of intervention, brief duration and with hand-picked staff are becoming, rightly, discredited. The ultimate objective should be to internalize the methodology into existing government/NGO systems, either as a stand-alone programme, or perhaps more appropriately as a supplement to broader programmes that already exist. Finally, however optimistic we may be about the potential of the approach, hype must be avoided. There is a real 
danger - attached to all new approaches — of creating beguiling 'development narratives', which weave a myth of success around flimsy evidence.

\section{World Overview of Conservation Approaches and Technologies}

The World Overview of Conservation Approaches and Technologies was established as a long-term programme, and a global network, in 1992 (WOCAT, 2000). The vision sprang from a realization that sharing of knowledge about soil and water conservation was generally poor. Knowledge was present, but often locked away in individuals and in 'grey literature'. Furthermore, formats were different, making comparisons difficult. Finally there was very little known about the extent of conservation: How widespread are various technologies (and approaches)? and How much vulnerable land in each country has actually been protected from degradation? The WOCAT's challenge was to tap that knowledge systematically and to develop a system of managing the information so that it could be used constructively in helping guide choices about approaches and technologies. Until now, the major focus has been on data collection and database management at central, regional and national levels.

The WOCAT is thus an ambitious programme, but one with a weight of professional commitment and personal dedication behind it, and with considerable institutional backing. As in all programmes of this nature there are complications (terminology; language; need for maintenance of standards; etc) which means that progress has been, inevitably, steady rather than rapid. Nevertheless WOCAT has made strides in data collection (from Africa, Asia, Latin America and Eastern Europe), and in setting up a database and query systems. By mid-2001, over 180 soil and water conservation technologies, and more than 100 approaches had been documented, and WOCAT has produced a CD-ROM with databases of technologies, approaches and images (WOCAT/FAO, 2001). An external evaluation gave considerable support to the concept, and to the project itself, while making constructive suggestions for the future (Stocking and Pozzi, 1998). One of the recommendations was for the rapid development of products: the technical handbook produced as a result of the PFI-WOCAT exercise (Mutunga and Critchley, 2001) is an example.

\section{METHODOLOGY}

The PFI-WOCAT exercise evaluated 18 innovations from PFI using the WOCAT methodology. These 18 were carefully selected from the PFI database of around 120 innovations in total. Each was considered to be a 'best-bet' technology (see note). Six were chosen from each of the three countries involved. These technologies deliberately covered a broad range of land husbandry initiatives. It was simultaneously ensured that male and female, old and young, innovators were all represented. Several of the innovations were well known by the local PFI teams, and some had been briefly described before. Others had scarcely been examined at all. Each of the 18 technologies were then subjected to WOCAT's 'questionnaire technologies' (QT). It was realized from the start that all would be weak in terms of input-output data, and that QT would ask many questions that would be difficult or impossible to answer quantitatively.

The field exercise, comprising training and data collection, was carried out alongside routine project activities over the period from December 1999 until May 2000. Each of the three national PFI coordinators had had some previous exposure to WOCAT, so the training was more of a topping-up/refresher exercise. In each country that process took one to two days. The coordinators, in turn, trained their field staff. Training included a background to WOCAT, the aims and objectives of the current exercise, and then a detailed examination of the contents of QT. It proved particularly important to clarify ambiguous or 'difficult' questions, as well as to explain what to do when data were lacking. In Kenya (to take an example) where the data collection covering six technologies was carried out as a concentrated campaign, this took three weeks. In that country, 12 individuals helped in enumeration. They were guided and assisted by the national PFI coordinator. As a rule of thumb, two data collectors took two to three days on a single QT. This amount of time was required to cover one or more visits to the farmers in question, as well as to refer to sources of background data at district headquarters. 
In addition to their role in training the national PFI coordinators, the two authors of this current article were responsible for filling a single questionnaire ('questionnaire approaches' or QA) that covers PFI's general methodology - with specific reference to Kenya. From May 2000 until the end of that year there was an intermittent process of cross-checking data, with queries referred back through the national coordinators, to the field enumerators. Finally data (from $18 \times$ QT and $1 \times$ QA) were entered digitally into the WOCAT database. During the first half of 2001 the data from the QTs, together with existing PFI characterization data (and supplementary information from field notes/discussions with PFI staff) were analysed and the publication (Mutunga and Critchley, 2001) was produced through Sida's Regional Land Management Unit (RELMA) in Nairobi. The only resources required in addition to regular project funding, were those needed for (a) training exercises, (b) digital data input and (c) preparation and printing of the publication.

\section{RESULTS: THE CASE STUDIES}

\section{Case Studies: Summary and Examples}

The tangible product resulting from the PFI-WOCAT exercise was a technical handbook (Mutunga and Critchley, 2001) which featured descriptions of 18 innovations and their associated innovators. While the data collected through WOCAT was used as the basis, these descriptions draw on a combination of information sources. The illustrated case studies were written in a simple style intended to be comprehensible to field workers and literate farmers. Six of those case studies are summarized here, maintaining a similar style and sequence. Each is presented according to a common format. There is an introduction to the farmer and his/her situation. This is followed by a technical description of the innovation. After this come some notes on costs and benefits, and then there is a section on interaction of the farmer innovator with PFI. After this follow comments on research questions/potential improvements to the innovation. There is then a concluding section on the significance of the innovation.

A summary of all 18 innovators/innovations studied under the exercise is presented in Table I. The following list explains headings of the columns in Table I.

Innovator:

Name and sex from PFI characterization data (1998/1999).

Innovation/initiative: The title used by PFI.

Brief description: Authors' summary.

Age innovator:

PFI characterization data.

Relative wealth:

PFI's qualitative assessment of wealth in local, relative terms.

Source idea:

PFI characterization data.

WOCAT category: QT question 2.2.2.2. Main category only considered.

PFI grouping:

Cost:

Categories proposed in Critchley et al., 1999a.

From QT estimates on labour inputs for construction (question 2.7.1): these are only approximate, and the categories used are ours and arbitrary: 100 person-days/ha is taken to divide 'high' from 'medium'. 'Low' $=25$ or less.

Benefit (long term): QT question 3.2.7 (b). Answer is farmer's own assessment.

Adoption:

QT question 3.4.2.1. Note: this is total known local adopters/adapters. Some spread results directly from PFI activity, some is 'natural' spread.

\section{Road Runoff Harvesting: Mr Musyoka Muindu, Mwingi District, Kenya (Table I, No. 1)}

Musyoka Muindu is about 70 years old. His farm lies by the side of the main tarmac road to Nairobi, some $10 \mathrm{~km}$ out of Mwingi town. In his endeavour to ensure family food security after retirement, and to boost his pension, he embarked on harvesting runoff from the road and distributing it round his cultivated fields.

Runoff is led to the farm from the surface of (and some from a culvert under) the tar road in an excavated channel of about $300 \mathrm{~m}$ length, which cuts through a neighbour's farm (see Figure 3 ). There are supplementary channels which lead extra runoff from an adjacent hillside. The catchment area is estimated to be at least 10 ha and probably more. This supplies water to a cultivated area of about 5 ha. The main channel leads runoff to the farm and into an 


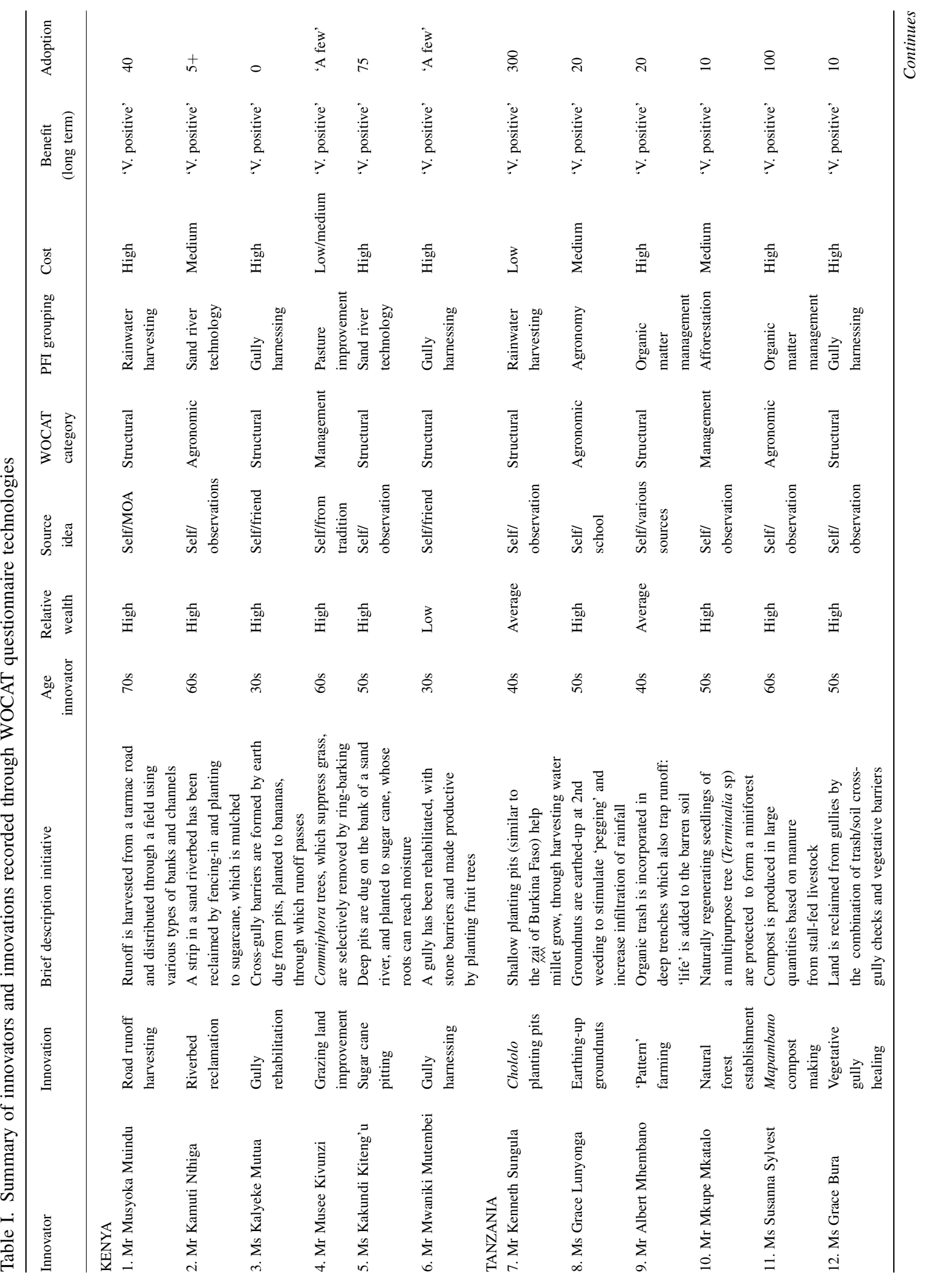


W. R. S. CRITCHLEY AND K. MUTUNGA

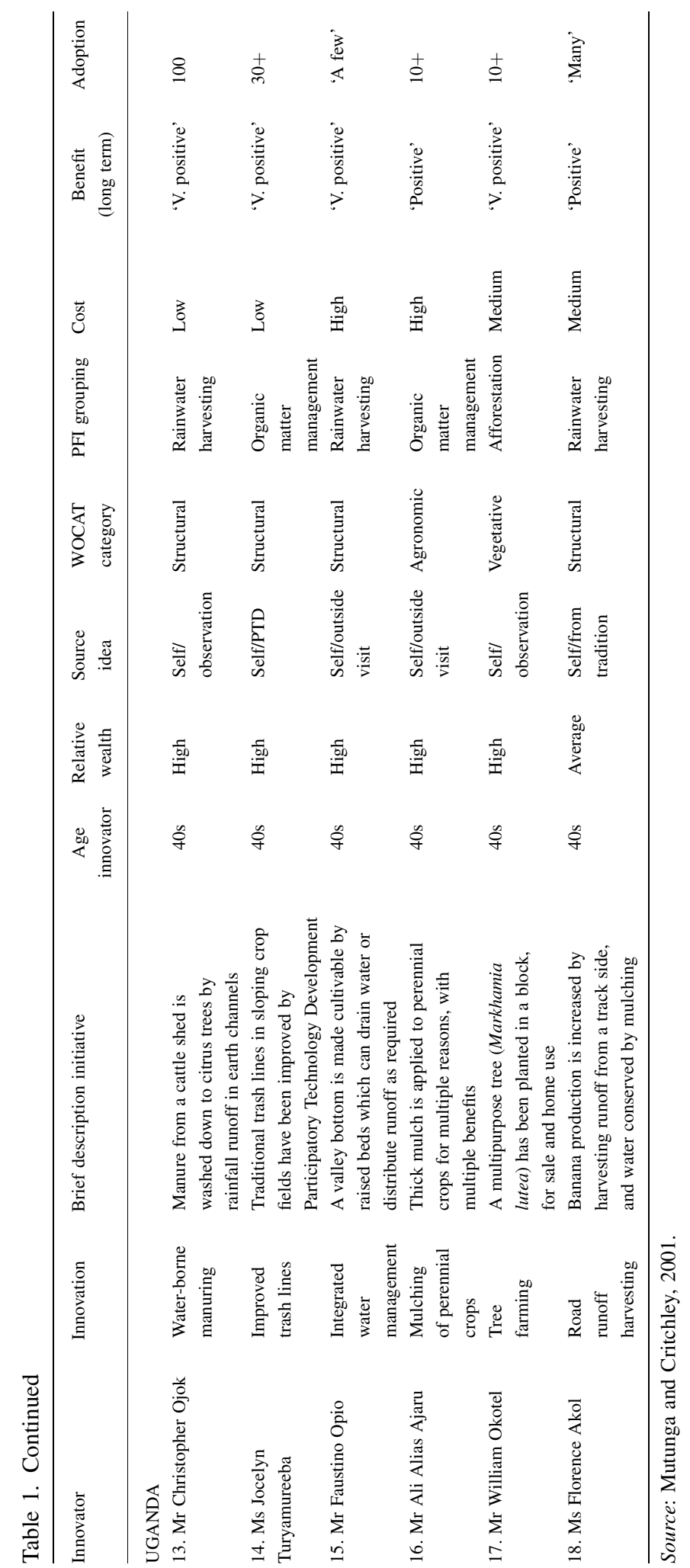




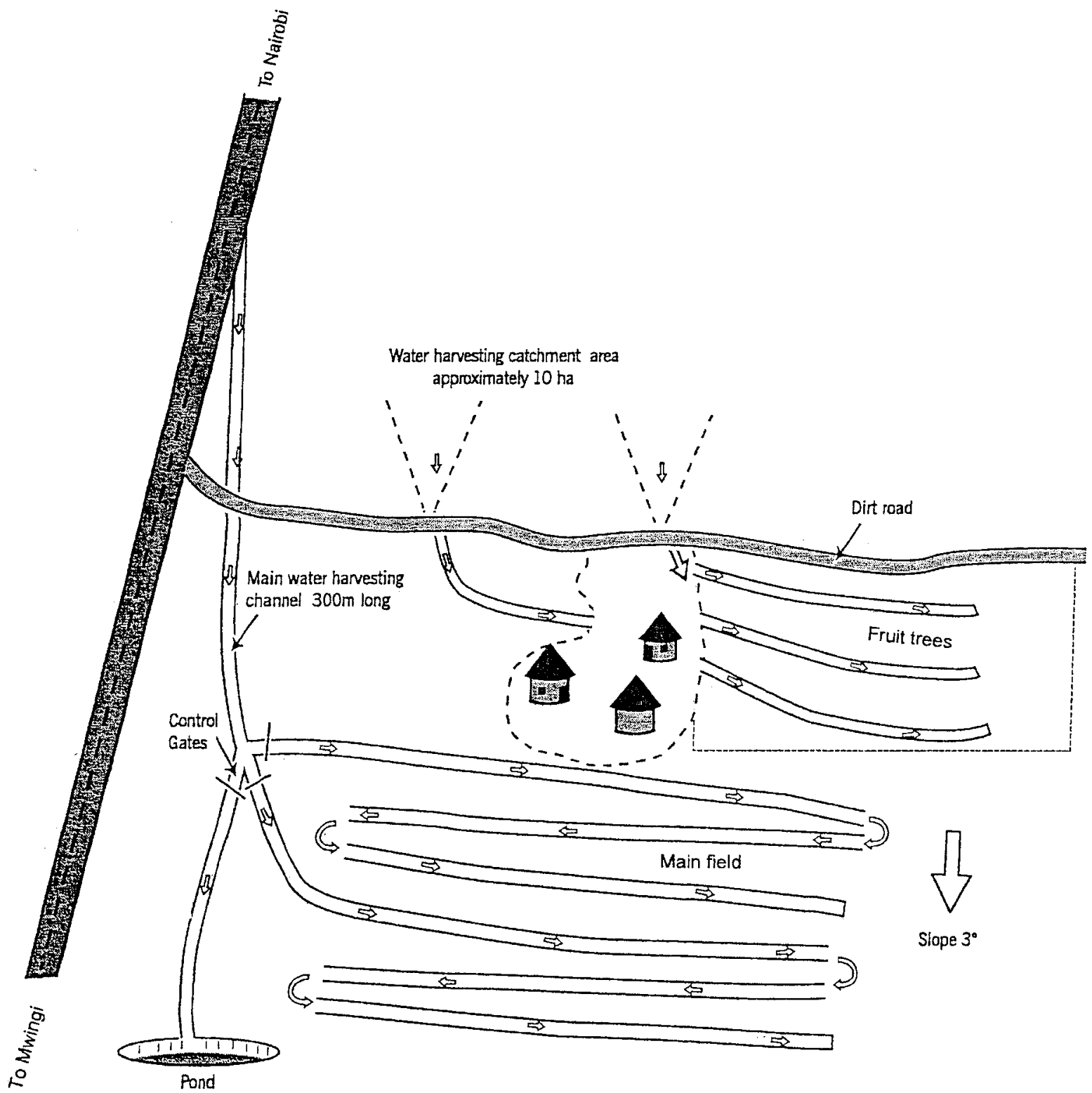

Figure 3. Musyoka's water harvesting system.

initial fanya chini structure (a channel with the earth bund downslope). When the runoff reaches the end of the channel it is diverted round into a similar structure, which leads the water in the opposite direction. Put simply, runoff water is conveyed in a zigzag fashion, or 'reticulated', through the farm. Some of the lower structures are fanya juu (channels with the soil thrown above). At certain points the farmer has put in water control gates so that certain channels can be bypassed, and surplus runoff can be diverted to a pond.

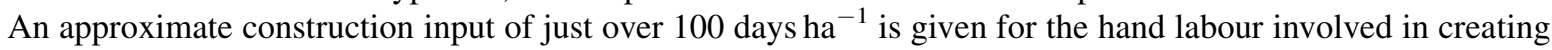
the infrastructure of bunds and channels. The annual requirement for maintenance is estimated at 10 persondays $\mathrm{ha}^{-1}$. This is less in a dry year, but can be much more due to damage caused by extra runoff during heavy 
rains. Clearly, while it is a low external-input system, this is a relatively expensive technology, and particularly demanding on labour. Nevertheless, because the system is directly linked to increased production, these are costs which can be recovered quickly. The benefits compared with investment costs are said by the farmer to be 'positive' in the short term and 'very positive' in the longer term.

Musyoka has been steadily developing his system since in 1993. This is largely as a result of hands-on experience and observations, but with some help from the Ministry of Agriculture and Rural Development. He had come to the attention of the Ministry before the start of PFI, and his technology was reported by Mwarasomba and Mutunga (in an unpublished report for the Ministry of Agriculture, Kenya, 1995) in their survey of positive experience in Kenya's semiarid areas. Visits outside the district, organized by PFI, have stimulated Musyoka to improve his system. His proximity to the tarmac road means that his farm is very accessible. PFI has taken about 800 farmers to visit Musyoka. The total adoption is recorded to be around 40 farmers. Musyoka has designed systems for two neighbours. However, several of those who have taken up water harvesting have not yet managed to achieve efficient runoff reticulation through their farms.

One improvement would be to assist farmers in layout and design. These road runoff harvesting systems can be very effective, but if not well designed or managed may lead to high maintenance requirements and an increased erosion hazard. An idea for improving Musyoka's system, which originated from the WOCAT data collectors who visited him, is that he could make his channels shallower to allow more water to spill over into his fields, rather than it being lost through deep percolation.

The significance of this initiative is that Musyoka has managed to adapt official soil conservation techniques (terracing using fanya juu and fanya chini methods) into a viable water-harvesting system. There were-and still are-no precise technical guidelines for this type of water harvesting in Kenya.

\section{Sugar Cane Pitting: Ms Lucia Kakundi Kiteng'u, Mwingi District, Kenya (Table I, No. 5)}

Kakundi is a married woman of about 50 years old, living in a remote part of the arid north of Mwingi District. Her farm of just over 20 ha is larger than the average for the area and she owns several cattle. She is therefore relatively resource-rich compared with her neighbours. Her initiative spans from the 1980s when she gained her inspiration by observing the movement of the watertable in holes dug in the banks of a sand river. ${ }^{4}$ Kakundi tried planting sugarcane cuttings in wide, deep holes just above the moisture zone, so that the roots could reach the water. She found that the cuttings did well even in the driest of seasons.

The technology involves planting sugar cane setts (stem cuttings) in square holes, excavated to a point where moisture can be sensed. Each hole is up to $1 \times 1 \times \mathrm{m}$ at the top, and from 0.6 to $0.75 \mathrm{~m}$ deep: the closer to the riverbank, the shallower the hole. The holes are spaced about $0.6 \mathrm{~m}$ apart within and between, rows (from edge to edge of holes). All work is done manually using hand hoes and shovels. Along the riverbank a band of vegetation is left for protection from flooding. Construction work is carried out in the dry season, when the watertable is about $2 \mathrm{~m}$ deep. Thereafter, a single sugar cane sett is planted in each corner of every pit, and manure applied during planting. Harvesting of the sugar cane continues for a period of about three-five years. During this time the pits gradually fill up with sediment. A new cycle then begins with the digging of fresh pits and the planting of new setts.

Despite the relatively large labour investment to establish the pits (not yet measured, but certainly above 100 person-days ha ${ }^{-1}$ ), Kakundi considers the long-term benefit to be 'very positive' in relation to the costs. The production value from the farm has about doubled in 10 years, and sales of sugar cane in the local market currently provide Kakundi with an estimated income of US\$500 per annum, which is an excellent return from the (approx.) 1 ha cultivated in this way. There have been problems with theft of produce, however, and long-term profitability will depend on the local market for sugar cane, which could readily become oversupplied.

Promoting Farmer Innovation has used Kakundi as a key training node for other farmers. It is estimated that in less than 3 years around 2000 farmers have been taken to view her enterprise and to hear her 'story'. She was filmed in the PFI video (UNSO-UNDP, 1999) so her innovativeness_-previously hidden away-is now widely known.

${ }^{4}$ Sand river $=$ a river with ephemeral surface flow. 


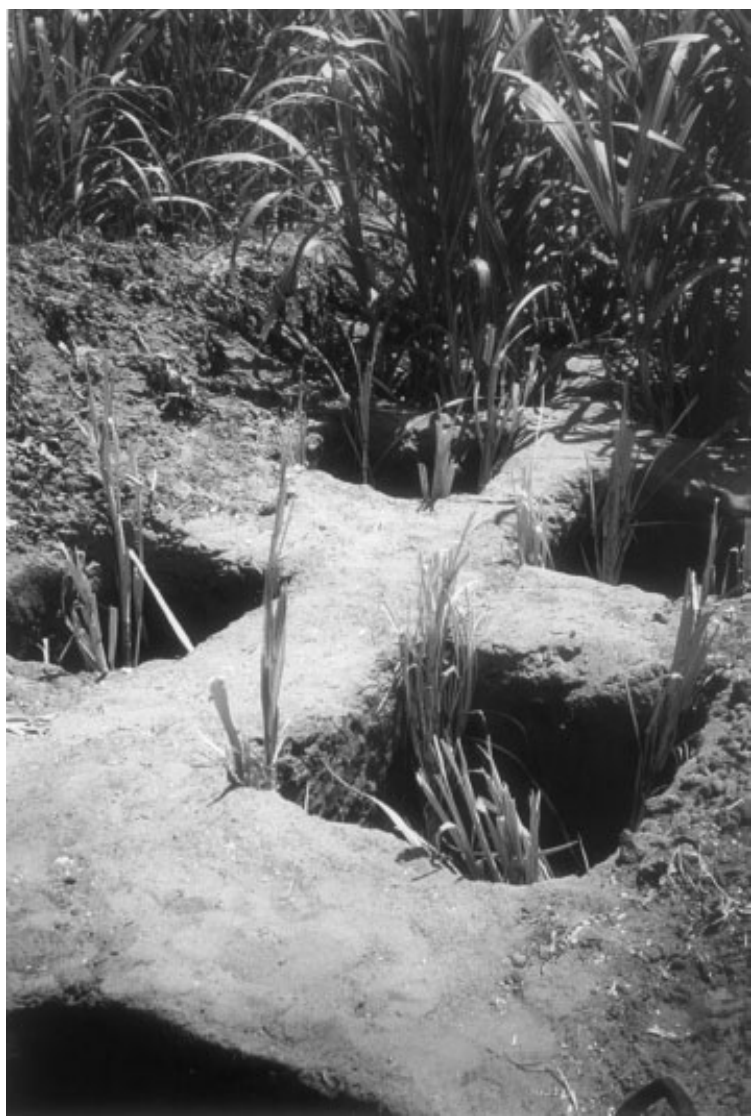

Figure 4. Sugar cane pitting.

According to the Kenya PFI team, Kakundi's technique is the most adopted under the national programme. In total about 75 men and women have copied her technology.

In terms of possible improvements to the system, floods can damage the structures and thus either protective dykes along the riverbank, or dense planting with perennial grasses as a buffer strip, could be helpful. There are various potential research questions. At the moment it is impossible to answer, quantitatively, the question: What is the increase in production associated with pits, compared to the extra costs? Kakundi has, however, recently started keeping simple input/output records based on treatment vs. control plots. Another interesting research question would be: To what extent, and how, have others modified her basic system to suit their production needs?

In many ways, Kakundi's initiative typifies what a project such as PFI is looking for. It is a simple technology that has proved popular in terms of adoption. Although this is a location-specific innovation, it is adaptable to a range of crops. It is directly related to increase in production and farm income, yet has associated environmental benefits as well through establishing dense, perennial vegetation close to a riverbank. Above all, the innovator herself, despite being illiterate and reserved, has proved to be a persuasive ambassador for her system.

\section{Chololo Planting Pits: Mr Kenneth Sungula, Dodoma Urban District, Tanzania (Table I, No. 7)}

Kenneth Sungula and his family are dependent on 4 ha of gently sloping land in Chololo village. The family owns no livestock, other than a few chickens. They grow pearl millet and cowpeas as their main annual crops. Neither Sungula nor his wife is literate. Sungula's technology dates back to 1978, when he stumbled upon the idea by accident. He noted that some plants growing in a small depression in the ground were strongly outperforming 
others nearby. He then began to experiment by deliberately digging small planting pits. Sungula claims that 'his stomach taught him' how to make the pits. These 'chololo pits', named after the local village, hold runoff. This is especially important in the establishment of crops in such a semiarid area, where the first rains can be erratic.

Pits of $0 \cdot 20-0 \cdot 25 \mathrm{~m}$ deep and $0 \cdot 20-0 \cdot 25 \mathrm{~m}$ in diameter are excavated in lines across the slope. The spacing is approximately $0.5 \mathrm{~m}$ from pit centre to pit centre within lines and $1.0 \mathrm{~m}$ between lines. During excavation, soil is heaped below each pit. The spaces between pits are not cultivated, and therefore act as microcatchments. Pits are made during the land preparation period, before the rains. Planting millet seed in the pits follows. Part of the excavated soil is returned to cover the seed, but a depression remains to collect harvested runoff water. Sungula has a stick, that he shows to visitors, to check depth.

It is estimated that crop yields have at least doubled as a result of the pitting. The labour input of constructing new pits is around 30-40 days ha ${ }^{-1}$. Annual maintenance of the pits is estimated at $15-20$ days ha $^{-1}$. Not surprisingly the benefits are considered to be 'very positive' compared with the costs by the farmer. From an ecological point of view, soil cover is improved, soil moisture increased and soil loss decreased.

Sungula was one of the first innovators identified by PFI. His farm has been regularly visited by outside farmers. In the last two years he has been working on improvements, driven by what he has seen on fellow innovators' fields. These include both fanya juu and fanya chini terraces, as well as water-harvesting channels leading water from a gully into his fields. The spread of this pitting technology has been quite rapid. The latest figures put the number of adopters at just over 300, though apparently it is mainly men who have taken to the system. According to PFI-Tanzania, most of this has occurred since systematic visits were organized by the project.

Sungula only keeps records of visitors to his plot, so the system remains technically unvalidated. A comparative study of chololo pits with similar systems found in the West African Sahel could shed light on possible improvements. What is immediately evident is the potential to add value to the pit system by applying compost/manure to increase soil fertility.

The chololo pits are particularly important for two reasons. First, this is an example of parallel evolution of a similar practice. These pits closely resemble the zai from Burkina Faso and tassa from Niger. Zai and tassa have

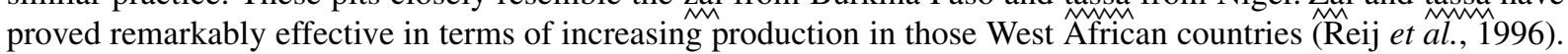
The second point of importance is that chololo pits are simple and cheap to make. They are thus an example of a

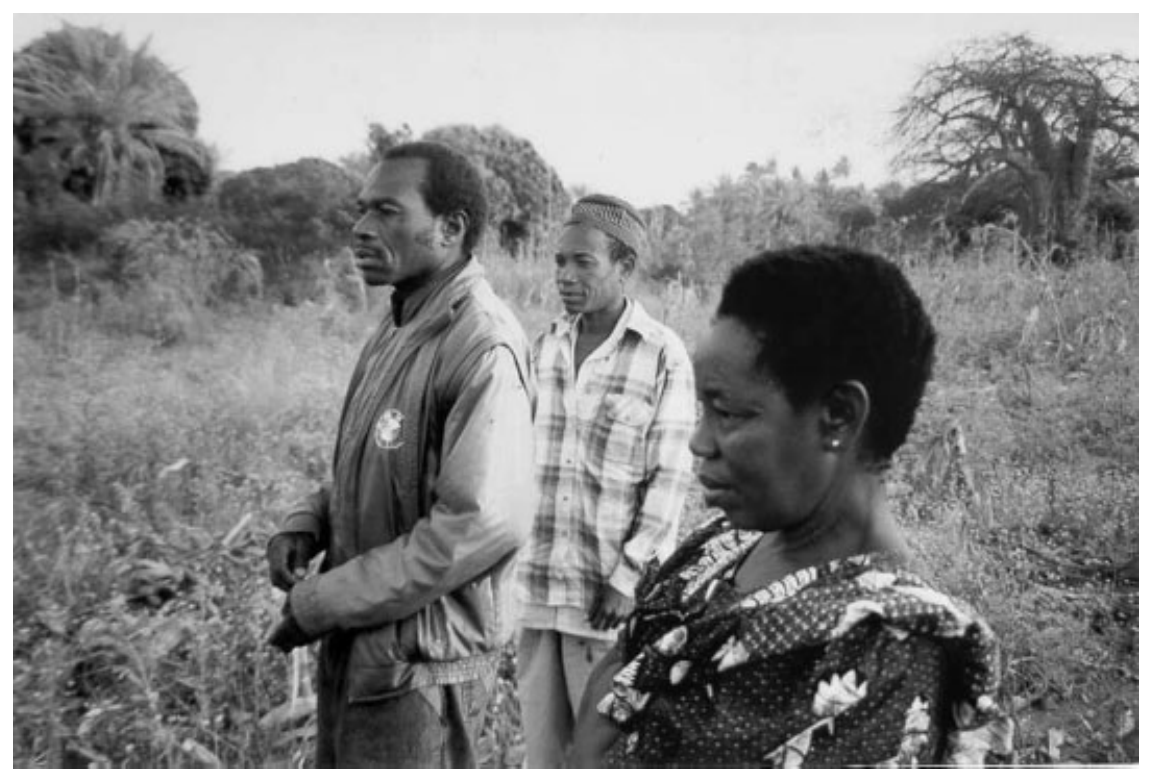

Figure 5. Kenneth (centre) with visitors. 
readily adoptable technology that clearly, and visibly, improves crop performance in semiarid areas, but are only suitable where hand, cultivation is carried out.

\section{Vegetative Gully Healing: Ms Grace Bura, Dodoma Rural District, Tanzania (Table I, No. 12)}

Grace is in her early 50s. Though her farm of 3 ha is not larger than normal, her homestead buildings indicate that she is rather above average in terms of wealth - something she has become through her own efforts. Grace is the main farmer in the family. Her husband is a retired teacher and professes no interest in the land. In 1982 Grace acquired, and decided to reclaim, a badly gullied field. After initial success, Grace is continuing to rehabilitate her land and to branch in other directions. She has bought a dairy cow for herself. Closer to home-where her cattle are stalled-fields are intercropped with pigeon peas, and manured with waste from the cattle and house compound.

This technology constitutes a gully-healing process. The starting point is to form a layer of trash and soil across the bed of a gully (a typical gully here is $3-10 \mathrm{~m}$ wide, and up to $2 \mathrm{~m}$ or more deep), reinforce it with pegs, and to build this up gradually in layers as sediment is captured behind it. On top of the barrier a dense line of tree cassava (Manihot glaziovii) is planted. Trash continues to be added to the now-living barrier until the gully is fully silted up. The barrier, around $1 \mathrm{~m}$ wide, then appears as a contour line across her land, and continues to function against erosion (see Figure 6). Tree cassava is not just a living structural support: its leaves are also a source of fresh vegetables. Where the gullies are more severe, she is testing cuttings of Commiphora africana.

Although there are no hard data on days worked, the labour requirement (which is the only major input) is considerable. Nevertheless, the farmer views the benefits as well worth while in the long term. It takes indeed four or five years before a gully is completely healed. Benefits include increased crop production and farm income as a function of increased cultivable area. The local ecological benefits are those associated with gully/erosion control, reclamation of land and improvement of soil quality.

Grace was one of the first innovators to be identified by PFI. Because her initiative is visually impressive, and because her farm is situated close to another farmer innovator, she receives many visitors through PFI. She welcomes them. Grace has been featured in both the PFI video and accompanying book (UNSO-UNDP, 1999; Critchley et al., 1999a). Ten farmers (five men, five women) are known to have followed Grace's technical approach. However, this technology is only relevant to those with gullies in their fields, and it requires not only a good deal of labour, but also constant observation and responsiveness. Visitors notice and appreciate the sense of creativity and integration of local resources. One interesting note is that Grace is making constructive use of

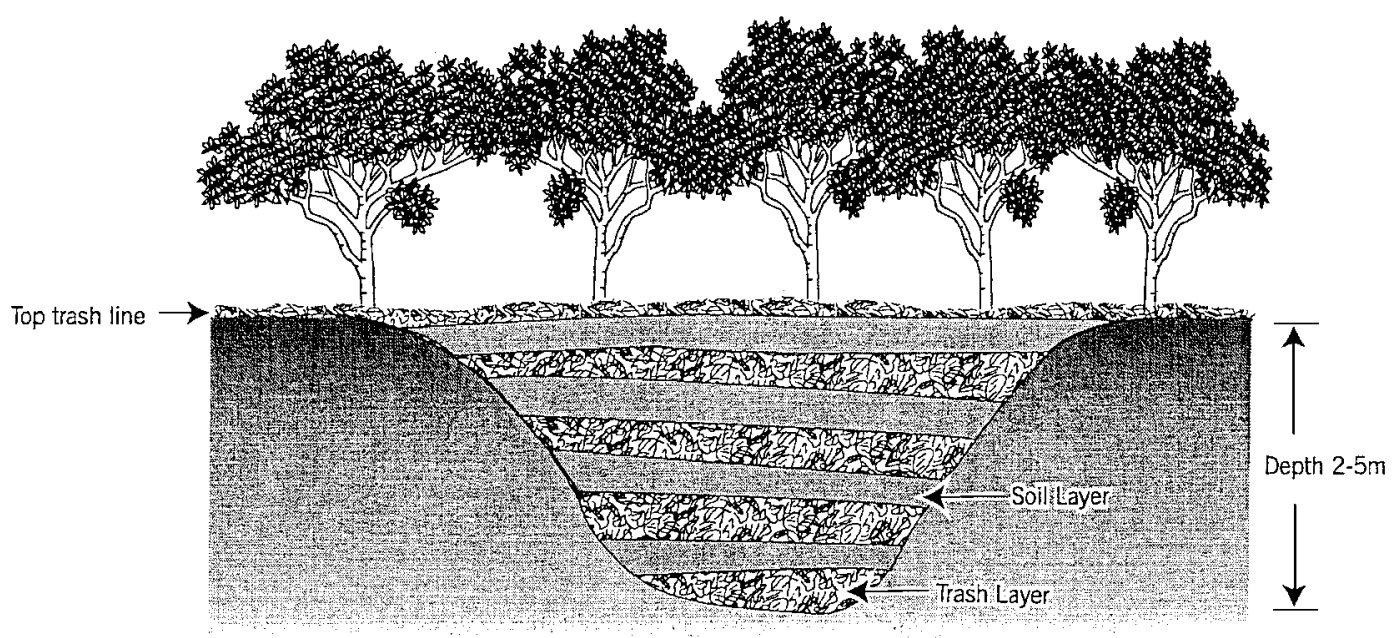

Figure 6. Vegetative gully healing. 
Commiphora, the very tree that another innovator (Musee Kivunzi: see Table I, no. 4) removes as a pest in his grazing land in Kenya. Both have good reasons for doing as they do.

An area of investigation, and possible improvement, would be to test different species of living barrier for effectiveness, and for intrinsic productivity. If the barrier was more remunerative in itself (fruit trees for example) then the 'adoptability' of the system might be increased.

The significance of this initiative is that Grace has, without outside guidance, managed to reclaim land from gullies, using vegetation to form barriers. There is no 'engineering' as such: no stone is involved, and earth is only used to supplement trash, rather than as a bund or barrier in itself. Furthermore, this is a woman's achievement, and helps to confirm that women's innovations are not necessarily household-oriented.

\section{Improved Trash Lines: Ms Jocelyn Turyamureeba, Kabale District, Uganda (Table I, No. 14)}

Jocelyn Turyamureeba is from Kabale District in southwestern Uganda. She is not directly associated with PFI, but a related programme entitled 'Indigenous Soil and Water Conservation'. Jocelyn is included here because of the particular importance of her trash lines, which, while not an innovation, is a local tradition that has been improved through participatory technology development. Jocelyn is the wife of the local agricultural extension agent. As her husband is employed, and they have a relatively large plot (6ha), they are better off than their neighbours.

The specifications of the improved trash lines (TLs) were developed as a result of collaborative experimentation by Jocelyn, three other 'trash line farmers' and researchers (Briggs et al., unpublished report IDG/98/11, Silsoe Research Institute, 1998; Critchley et al., 1999b). The main difference is that the new specifications mean smaller, closer and longer duration TLs than the common tradition. These adjustments optimize the impact of TLs on soil fertility. Vegetative material (stover, weeds, etc.) is collected during primary cultivation, and heaped along the approximate contour, across the fields of annual crops. This is supplemented during weeding. The recommended spacing between TLs is 5-10 m, depending on the slope. The material available determines the cross-section of the TL ( $\pm 0.5 \mathrm{~m}$ wide and $\pm 0.3 \mathrm{~m}$ high initially) (see Figure 7). Improved TLs are left in place for 3-4 seasons (Kabale has two growing seasons per year) before being dug into the soil. New TLs are then established between the sites of the former strips.

The costs associated with establishing TLs basically comprise labour only, which amounts to approx. thirty days $\mathrm{ha}^{-1} \mathrm{yr}^{-1}$. Maintenance costs are absorbed as a part of regular weeding. Gross margins from fields with TLs have been calculated to be 50 per cent higher than those without (Briggs et al., unpublished report as above 1998). This is largely due to the effect of improved fertility when the trash decomposes and is incorporated into the soil: thus an alternative name, 'mobile compost strips'.

Jocelyn began cooperating as a farmer-researcher in 1995 with a previous project investigating traditions of land husbandry (Briggs et al., unpublished report as above 1998; Critchley et al., 1999b). Since then she has continued to play a key role in disseminating the technology. She has also benefited from several study tours outside the area. When investigated by Miiro et al. (2001), seven farmers (six women, one man) were found to have copied the improved technology directly from Jocelyn. On average four more had then copied from each of the original seven, implying a total in excess of thirty. Although the expression 'copied' is used here, at least some of the secondgeneration followers had made (unspecified) adaptations. Locally, about 30 per cent of the land users have adopted

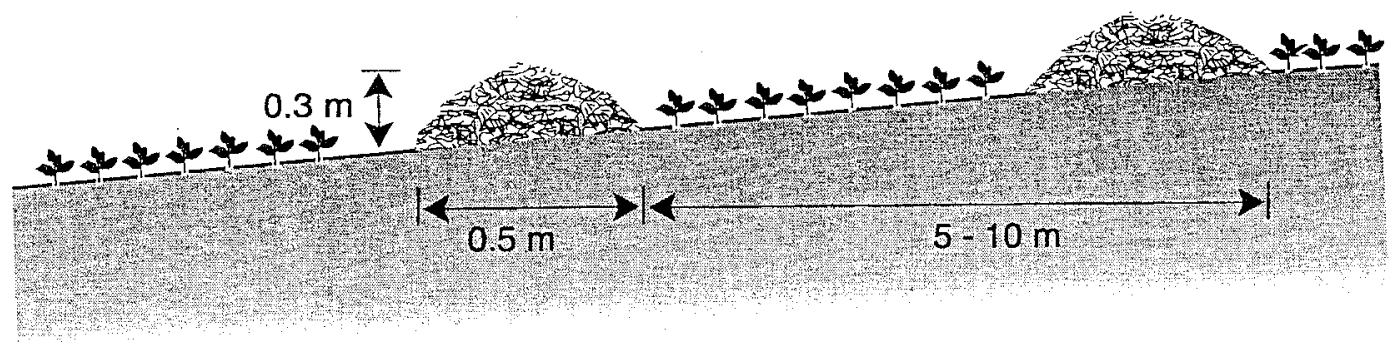

Figure 7. Improved trash lines. 
some form of TLs (though not necessarily improved, and not necessarily from Jocelyn) with women farmers in the majority.

Participatory research has been carried out on TLs and recommendations made for improvements. What is now necessary is to follow up the question of adoption again in detail, this time concentrating on the extent to which the improved specifications have been followed or otherwise.

This is an important technology for three main reasons. First, it is a tradition, which has been improved through participatory technology development processes. Second, Jocelyn is supported by her husband-an extension worker-so this constitutes an example of 'practising what you preach'. Third, it is a simple effective technology, particularly appropriate for, and popular with, women.

\section{Mulching of Perennial Crops: Mr Ali Alias Ajaru, Katakwi District, Uganda (Table I, No. 16)}

Ali Alias Ajaru is an enthusiastic farmer and local opinion leader. He is constantly testing new ideas, and feels a vocation to teach others. Ali is in his 40s and has three wives. He is better off than the average householder in this dry and remote part of Katakwi District, with some 20 ha of land. It would be a simplification to portray Ali as being a man with just one innovation: he is experimenting and trying out a very wide range of different practices. In fact he was originally selected by PFI for planting a contour line of pineapples within other crops as a barrier against erosion. Some of the ideas he has picked up on his own travels and PFI-sponsored study tours, including this idea for the mulching. Others he has simply worked out for himself. In addition to mulching he has various systems of water harvesting (including rooftop to underground tank), as well as retention ditches, vegetative barriers, agroforestry and composting. He even uses fermented human urine to kill banana weevils. Ali says of himself that he 'does not allow one drop of water to escape'.

Bananas are planted on raised beds of $5 \times 20 \mathrm{~m}$, separated by furrows $0.5 \mathrm{~m}$ deep. Setaria grass is planted as a fringe around the beds, preventing loss of soil into the furrows. Mulch is applied to an initial thickness of about $0.15 \mathrm{~m}$, on top of a layer of manure or compost, over the whole banana bed. Citrus and pineapples are also mulched in a similar way. Various materials are used for mulching, including groundnut trash, cereal stover and grass.

Production of various crops, and farm income are said to have increased as a result of the mulching. The recurrent labour cost associated with mulching is estimated by the farmer to be 150 days $\mathrm{ha}^{-1} \mathrm{yr}^{-1}$. Compared with this cost, the long-term return is considered to be positive.

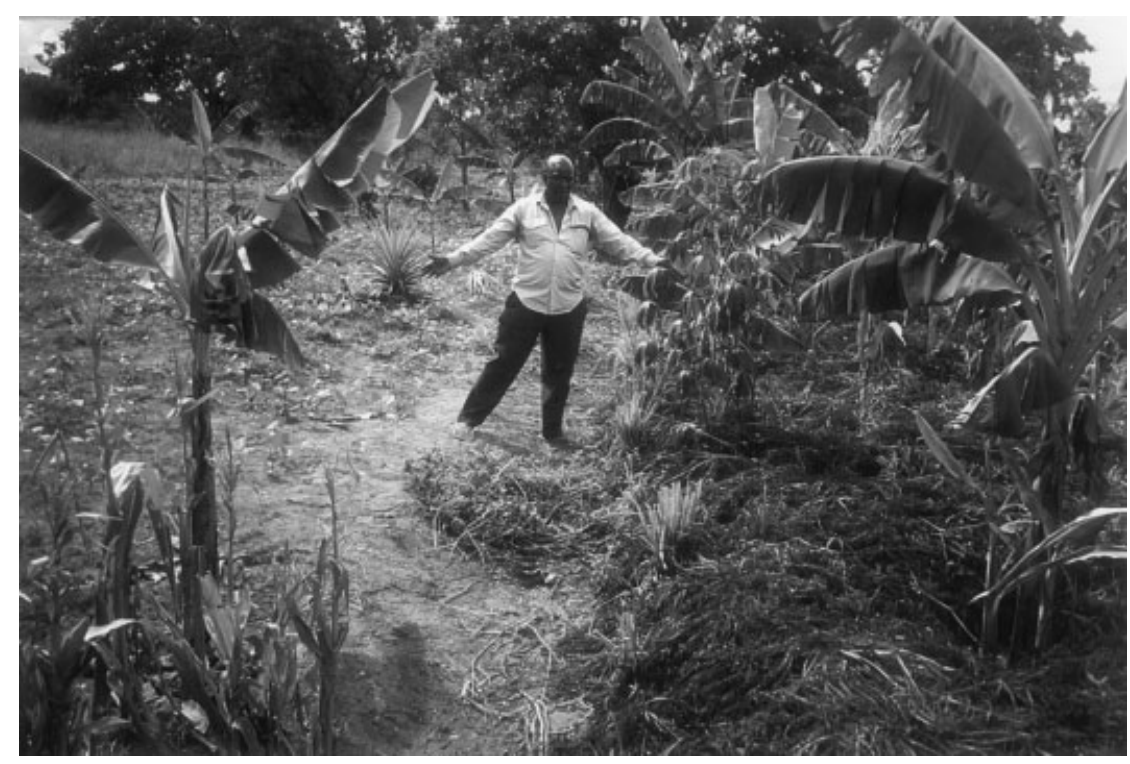

Figure 8. Mulching of perennial crops compared with control plot. 
Ali was one of the originally identified and screened farmers under PFI-Uganda, and has played a crucial role in the programme. He has been on study tours organized by PFI, and has probably brought back more ideas than anyone else under PFI-Uganda. For example, as a result of a tour to central and eastern Uganda he started testing seven different technologies. He has also been the focus of PFI-organized visits by farmers, and has furthermore trained a large number of villagers (he claims over 240) through his own voluntary initiative. At this relatively early stage only around 10 others have taken up mulching in the neighbourhood.

In the case of Ali, who is a teacher by nature, it would be valuable if he could back up his comparison of mulched against non-mulched with some hard factual evidence. This he has begun, through simple record keeping of inputs and outputs.

Mulching is obviously only an 'innovation' in very local terms. It is a well-known practice in Uganda, particularly in bananas, but is not common in Katakwi. What is especially striking about Ali's approach is that he has set up treatment and control plots side by side to observe the difference between them, and to use the comparison to demonstrate his point to others. A visit to his farm is bound to have an impact on other farmers as there are so many different trials and proven practices to be seen. But at the root of all of these are the guiding beliefs that water should not be lost out of the farm, and that organic matter should be recycled.

\section{DISCUSSION AND ANALYSIS}

This section briefly looks analytically at two aspects. First, the innovators and the technological innovations. All 18 (as presented in Table I) are considered. Second, we analyse how has the PFI-WOCAT link has worked in practice.

\section{The Innovators and the Innovations}

The innovators were selected on the basis of having developed especially promising ('best-bet') technologies. Although the selection was deliberately made to include a wide range of technologies and individuals (women and men, young and old); these people are broadly representative of what PFI considers 'good innovators'. In fact the age range and gender split conform quite well to the overall population of innovators uncovered by PFI. ${ }^{5}$ Of the 18 innovators addressed by the PFI-WOCAT exercise, 7 are women and 11 men. PFI initially had problems identifying women innovators, then a deliberate campaign helped partially correct this (Ong'ayo et al., 2001). To what extent this selection represents the true population of innovators in land husbandry is an unknown.

It is clear that innovators are often relatively old (Table I). This is logical: it takes time and experience to see, think through and test new ideas - a point also highlighted by Reij and Waters-Bayer (2001b). Innovation on the land commonly occurs during retirement. A crude estimation of wealth was attempted through the PFI characterization forms (which preceded the WOCAT exercise) and by discussions with field agents. This was based on farm size, livestock holding, and employment in the family and so forth. Bearing in mind that all of the innovators are absolutely poor, a large majority (14 of the 18) come from relatively wealthy households in local terms. This does not simply mean that either (a) only the relatively wealthy innovate, or (b) innovation leads to wealth creation, but both statements are certainly partially true. In particular (b) is clearly articulated in a number of the case studies. Finally, an analysis of the primary source of the ideas demonstrates that 'thinking through' and observation of biophysical processes by the innovators was the most important factor behind nearly half of the innovations. The next most important main stimulus was visiting friends and/or travel. It is important to note here, in the context of the PFI-WOCAT exercise, that very little data on the innovators themselves was picked up through the WOCAT QT.

If the innovations are categorised according to WOCAT (main category only: ignoring combined categories for simplicity), 11 are 'structural', 4 'agronomic', 2 'management' and 1 'vegetative'. While this WOCAT system is

${ }^{5}$ See Critchley et al., 1999a for a characterization of the first batch of innovators identified by PFI. 
useful, there are some anomalies. For example the trash lines belonging to Jocelyn Turyamureeba (Table I, no. 14) are classed under WOCAT as 'structural' because they last, just, for more than one year: 'agronomic' may seem more logical as they hardly differ in principle from the mulch of Ali Alias Ajaru (Table I, no. 16). One may also wonder about Kenneth Sungula's modest-sized planting pits (Table I, no. 7), being officially classed as structural' ${ }^{6}$

If we use the function-oriented grouping used by PFI (Critchley et al., 1999a), and followed broadly by Reij and Waters-Bayer (2001b) which is supplementary to the WOCAT system rather than an alternative, then five technologies fall under 'rainwater harvesting', four 'organic matter management', three 'gully control/harnessing', two 'afforestation', two 'sand river technology/water table management', one 'agronomic' and one 'pasture improvement' (Table I). This range of technologies does represent, as it was intended to, the spread of land husbandry innovations that PFI has identified in these dryland areas. Some of the technologies are variations of each other (for instance the three examples of gully harnessing); others could potentially work in a complementary way (for example road runoff harvesting and chololo pitting). In one comparison (compost making vs. trench cultivation) it could be argued the former is already a partial evolution of the latter.

The subsections on cost and benefits are very weak in terms of quantification. The reason is simply that none of the innovations has yet been adequately validated in numerical terms, either by the land user or by research agents. Where figures are given, they are generally farmers' estimates that we have accepted as credible after relating to comparable, documented technologies. If an arbitrary and qualitative rating of 'high input' vs. 'medium or low input $^{7}$ is used to categorize technologies, the innovations fall roughly half-half into these categories. Naturally the structural measures tend to be relatively high input. What is striking, but not surprising, is that the very large majority of the input comprises hand labour. These are all, therefore, low-external input systems.

Data on economic benefits are correspondingly weak. We have relied on the answers to the QT question: How do the benefits compare with the investment costs $(a)$ in the short term and $(b)$ in the long term $?^{8}$ Although this can only yield non-quantitative data, it does give an idea of what the innovators perceive about the worth of their technologies. All answer either 'very positive' $(n=16)$ or 'positive' $(n=2)$ in the long term. Even when the short term question is considered, 16 of the 18 answered 'slightly positive' or better. What is abundantly clear is that every one of the innovations has been developed with the aim of improved plant production (for food, cash income or both), either as an immediate, primary purpose (the large majority) or sometimes as a combined aim, together with the need to control gullies or control runoff. Here is a central message: conservation is never divorced from production in the eyes of the innovators. A final point regards the reliance of the innovators, in many cases, on a locally marketed cash crop (including fruits, sugar cane, groundnuts and timber products) to realize the economic benefits. These are markets that can be easily saturated. The benefit associated with adoption of innovations will not therefore be so great if the best market opportunities have already been exploited by the original innovators.

With respect to numbers of adopters of the technologies, the data gathered have variable reliability. Again these comprise estimates (confirmed by, or originating from, extension agents), but are often based on records of names kept by the innovators themselves. Adoption has taken place, in all cases, without material incentives. Technically speaking it may be copying or further adaptation. There are some indications from an informal PFI impact assessment in Uganda to show that further adaptation after/during 'adoption' occurs more often than not. Promoting Farmer Innovation has only stimulated this process of spread. It is partially spontaneous, and may also have been encouraged by other organizations. Some technologies have hardly spread at all. This may be to do with site specificity of the innovation, or high labour input required. However high cost/labour input is perhaps not as great an issue as might be thought, as long as the benefits are commensurate. Taking the four most popular innovations, those of Christopher Ojok, Kenneth Sungula, Ms Susanna Sylvestra and Ms Kakundi Kateng'u (Table I), the first two are low input, the last two high input. The other aspect of adoption is the intangible element,

\footnotetext{
${ }^{6}$ Since this paper was drafted, the WOCAT categorization system has been modified such that trash lines and small planting pits are now classed indeed as 'agronomic'.

${ }^{7}$ Based on per unit area, initial establishment cost. A figure of above 100 persondays ha ${ }^{-1}$ has been used as an arbitrary dividing line to denote 'high' input; below 25 person-days $\mathrm{ha}^{-1}$ is 'low' input.

${ }^{8}$ There are no time scales attached to these questions in QT (3.2.7) which were put to the innovator. It can be answered 'v. negative/negative/ slightly negative/neutral/slightly positive/positive/v. positive'.
} 
namely the stimulation of 'innovativeness'. Have visitors to innovators been stimulated to think through their own problems? It certainly appears that this has taken place. But the measurement of this phenomenon is not clear-cut, and is outside the scope of the current exercise.

\section{The PFI-WOCAT Exercise}

Apart from its direct purpose in collecting and helping to analyse data, this PFI-WOCAT exercise was a test of the complementarity of two programme initiatives: How well could WOCAT serve PFI, and to a more limited extent, vice versa? Initially, WOCAT was used as a stand-alone exercise to make inventories of technologies and approaches in specific countries or international regions, using earmarked funds. This situation is changing. Decentralization of programmes - within South Africa for example-has occurred since 1998. However the situation reported here, WOCAT has been tested for a specific purpose, within an on-going project, with (mainly) the project's own resources. PFI had already gone through an internal process of characterization of its innovators and their innovations, but the question was: How much value could WOCAT add to the description and evaluation of those technologies?

The clearest finding from the exercise was expected: there was a lack of hard data in all cases to satisfy the demands of the WOCAT technologies questionnaire (QT). This was unsurprising since it is often the case, even, when WOCAT's QT is applied to well-known, technically recommended practices. Often WOCAT has uncovered a surprisingly poor level of quantitative knowledge among soil and water conservation specialists. So, for farmers' innovations which have only just been exposed, it will obviously be an even greater shortcoming. From this arose another problem: that of injudicious guesstimation. Several times, during cross-checking of questionnaires, figures turned up that were clearly grossly inaccurate ${ }^{9}$ or simply inconsistent. These had to be filtered out, and referred back to the enumerators. When this was done, a reasonable level of credibility was arrived at.

It also became apparent that not all the innovations fitted neatly into the QT, because PFI has a rather wider technological span (land husbandry in its widest sense) than WOCAT. It was difficult, for example, to 'massage' a composting system (Table I, no. 11) into the questionnaire. Furthermore, specific questions were not easy to answer for individual initiatives - those regarding areal coverage for example. And some innovations are not fixed technologies; they are constantly evolving and are thus 'moving targets'. There was also tedious repetition of background information, which was not surprising since in each country the innovations are clustered, physically, close together. This in fact could have been avoided by identifying which questions need only be asked once for a given cluster of technologies. A number of weaknesses in clarity of the questions in the QT showed up, though these were as much to do with inadequate training of enumerators and lack of time than the questions themselves. ${ }^{10}$ One more specific point regarded the diagrams where (a) an 'artist's impression' and (b) a 'technical drawing' are both asked for. Not only was there confusion between the two, but, as freely admitted, and in common with most people, many of the enumerators simply can not draw very well.

Various themes emerge from the comments given in the evaluation section of the QT (Annex T2) where the enumerators are asked to reflect on the process they have gone through. Several of the enumerators found the questionnaires long and tiresome. But, interestingly, there is no mention of the farmers being fatigued. Many of them clearly enjoyed being closely questioned about their practices, and appreciated the interest shown in them. Another point was that the questionnaire caused the enumerators to think though a number of aspects that they had not considered before. This they appreciated. Finally, the paucity of available data became very clear to all.

Three general lessons about WOCAT field exercises, none of them entirely new, are supported by our experience. The first is that there simply must be enough time dedicated to training in the enumeration of the questionnaires. Virtually the only way to do this satisfactorily is for an experienced 'WOCATeer' to work oneon-one with a field specialist/enumerator on at least one real-life case study. On balance, not enough time was

\footnotetext{
${ }^{9}$ For example one labour input given for a simple in-field technique was found to be unbelievably high on cross-checking (equivalent to levels used in construction of bench terraces). The farmer had been asked to estimate his daily input 'per hectare'. This was a concept he clearly did not understand. When taken to the field afterwards, he marked out an area that he could achieve in a single day. His wife was asked the same independently. The two answers were consistent. The result was a labour input around 10 per cent of the original guesstimate.

${ }^{10} \mathrm{~A}$ few ambiguities turned up: these will be fed into the ongoing WOCAT process of upgrading the questionnaires.
} 
dedicated to that training during the current exercise, nor was adequate time allocated to completion of questionnaires in the field. A second general lesson is that data must be carefully cross-checked after submission of questionnaires, by (again) an experienced WOCATeer. Our experience is that there are always a number of dubious answers given, and sometimes there are obvious contradictions. Furthermore, some questions are simply overlooked.

Perhaps the third general lesson learnt is the most important one. WOCAT can be useful within a project, to describe technologies, approaches and areal extent of conservation. WOCAT should be looked upon as a service provider, responding to specific project needs, while continuing its more global role. But the WOCAT data will almost always need to be supplemented by other information as well to maximize its utility to the project. Selected data (but not all) from such a WOCAT-project initiative will also be a valuable addition to the global WOCAT database. As we have noted above, one of the main problems with the current exercise was the lack of readily available facts and figures. This led to some frustration and the problem of inaccurate estimates and guesses. But in this final lesson lies an opportunity. WOCAT could perhaps best be incorporated into such a project from the start, to help guide technical validation of specific, best-bet technologies, and thus to help evaluate them. That way, WOCAT would be mapping out a path for technical monitoring. Relevant data would be built up gradually, rather than being demanded abruptly and with inadequate preparation.

\section{CONCLUSION}

The PFI-WOCAT exercise has been useful at two levels. First, it has directly benefited PFI in increasing, and spreading, knowledge about specific best-bet innovations. Second, it has tested the use of WOCAT tools in a single project context. With respect to the first aspect, while only one step in the technical validation process, it has helped in building up the project database (while also adding to WOCAT's global databank), in documentation and in highlighting possibilities for further investigations and potential improvements. It has formed the basis for a technical publication (Mutunga and Critchley, 2001) which provides functional guidelines and some discussion. During the process of reflection and analysis under this exercise, it was reconfirmed to most who took part, that the 'innovator approach' can be a powerful mechanism in developing more appropriate technologies. At a higher level, it can help to redefine relationships between farmers, researchers and extension agents. However, one of the potential dangers of this new approach is unsubstantiated claims-for technical performance, for costeffectiveness, for spread of innovations and so forth. Monitoring and evaluation are common weaknesses in these sorts of programme, and here WOCAT can help. With respect to the second aspect, that is the complementarity of the two approaches, WOCAT tools can evidently be picked off the shelf and used constructively within a project. In this specific exercise, PFI had already collected a basic dataset, but WOCAT provided a valuable supplementary framework to help validate the technologies. This was not, though, without difficulties including lack of data, and inadequate of training of personnel. Finally, the WOCAT questionnaire on technologies, while helpful in providing a snapshot evaluation, could be even more potent if used as a tool to guide monitoring and evaluation of technologies over a period of time.

\section{ACKNOWLEDGEMENTS}

The authors would like to thank all those who helped in the process of data collection under this exercise; there are too many all to be named. But particular thanks are due to the three national PFI project coordinators, Patrick Lameck (Tanzania), Alex Lwakuba (Uganda) and Charles Mburu (Kenya). We are grateful also to the Regional Land Management Unit (RELMA) in Nairobi, where the Director, Ake Barklund, generously committed resources to production of the technical report, and to Alex Oduor for coordinating the publication. RELMA kindly allowed us to use that report as the basis for this paper. Thanks also to WOCAT for financial assistance and support. We are furthermore grateful to the Netherlands government, who sponsored PFI. Finally, thanks to two anonymous referees whose comments were most valuable. 


\section{REFERENCES}

Blaikie P, Brookfield H. 1987. Land Degradation and Society. Routledge: London and New York, NY.

Chambers R, Pacey A, Thrupp LA (eds). 1989. Farmer First: Farmer Innovation and Agricultural Research. Intermediate Technology Publications: London.

Critchley WRS. 2000. Inquiry, initiative and inventiveness. Farmer innovators in East Africa. Physics and Chemistry of the Earth 25: 285-288.

Critchley WRS, Mosenene L. 1996. Individuals with initiative: network farmers in Lesotho. In Successful Natural Resource Management in Southern Africa, Centre for Development Cooperation Services, Vrije Universiteit Amsterdam (ed.). Gamsberg Macmillan: Windhoek; 71-81.

Critchley WRS, Reij C, Willcocks TJ. 1994. Indigenous soil and water conservation: a review of the state of knowledge and prospects for building on traditions. Land Degradation \& Rehabilitation 5: 293-314.

Critchley WRS, Cooke R, Jallow T, Lafleur S, Laman M, Njoroge J, Nyagah V, Saint-Firmin E (eds). 1999a. Promoting farmer innovation. Workshop Report No. 2. Regional Land Management Unit (RELMA): Nairobi.

Critchley WRS, Miiro HD, Ellis-Jones J, Briggs S, Tumuhairwe J. 1999b. Traditions and innovation in land husbandry: building on local knowledge in Kabale, Uganda. Technical Report No. 20. Regional Land Management Unit (RELMA): Nairobi.

Gündel S, Hancock J, Anderson S. 2001. Scaling Up Strategies for Research in Natural Resource Management: A Comparative Review. Natural Resource Institute: Chatham.

Guijt I. 1998. Participatory monitoring and impact assessment of sustainable agriculture initiatives. SARL Discussion Paper No. 1, July 1998. IIED: London.

Gupta A. 1998. Respecting, recognising and rewarding local creativity: knowledge networks for biodiversity conservation and natural resource management. Indian Institute of Management: Ahmedabad (mimeo).

Hurni H. (with the assistance of an international group of contributors). 1996. Precious Earth From Soil and Water Conservation to Sustainable Land Management. International Soil Conservation Organisation and Centre for Development and Environment. University of Berne: Berne.

Ong'ayo M, Njoroge J, Critchley WRS. 2001. Women and innovation: experiences from Promoting Farmer Innovation in East Africa. In $A$ Source of Inspiration: Farmer Innovation in Africa, Reij C, Waters-Bayer A (eds). Earthscan: London; 110-121.

Miiro HD, Critchley WRS, Van der Wal A, Lwakuba A. 2001. Innovation and impact: a preliminary assessment from Kabale, Uganda. In $A$ Source of Inspiration: Farmer Innovation in Africa, Reij C, Waters-Bayer A (eds). Earthscan: London; 198-217.

Mutunga K, Critchley WRS. 2001. Farmers initiatives in land husbandry. Promising technologies for the drier areas of East Africa. Technical Report No. 28. Regional Land Management Unit: Nairobi.

Nielson F. 2001. Why do farmers innovate and why don't they innovate more? In Farmer Innovation in Africa: A Source of Inspiration for Agricultural Development, Reij C, Water-Bayer A (eds). Earthscan: London; 92-102.

Reij C, Water-Bayer A. 2001a. Entering research and development in land husbandry through farmer innovation. In Farmer Innovation in Africa: A Source of Inspiration for Agricultural Development, Reij C, Waters-Bayer A (eds). Earthscan: London; 3-20.

Reij C, Waters-Bayer A. 2001b. An initial analysis of farmer innovators and their innovations. In Farmer Innovation in Africa: A Source of Inspiration for Agricultural Development, Reij C, Waters-Bayer A (eds). Earthscan: London; 77-91.

Reij C, Scoones I, Toulmin C (eds). 1996. Sustaining the Soil: Indigenous Soil and Water Conservation in Africa. Earthscan: London.

Richards P. 1985. Indigenous Agricultural Revolution. Hutchinson: London.

Pretty JN. 1995. Regenerating Agriculture: Policies and Practice for Sustainability and Self-reliance. Earthscan: London.

Scarborough V, Killough S, Johnson DA, Farrington J (eds). 1997. Farmer-led Extension: Concepts and Practices. IT Publications: London.

Stocking M, Pozzi A. 1998. External Evaluation of WOCAT. Switzerland Agency for Development and Cooperation: Berne.

Tiffen M, Mortimore M, Gichuki F. 1994. More People, Less Erosion: Environmental Recovery in Kenya. Wiley: Chichester.

UNSO-UNDP. 1999. Promoting farmer innovation: the video. Regional Land Management Unit: Nairobi.

UNSO-UNDP. 2001. Promoting farmer innovation: final report. UNSO-UNDP: Nairobi (mimeo).

Van Veldhuizen L, Waters-Bayer A, De Zeeuw H. 1997. Developing Technology with Farmers: A Trainer's Guide for Participatory Learning. Zed Books: London.

WOCAT. 1999a. Questionnaire approaches. Group for Development and Environment. University of Berne: Berne.

WOCAT. 1999b. Questionnaire Technologies. Group for Development and Environment. University of Berne: Berne.

WOCAT. 2000. Knowledge for sustainable soil and water management (Brochure). Group for Development and Environment. University of Berne: Berne.

WOCAT/FAO. 2001. World Overview of Conservation Approaches and Technologies. CD-ROM. Land and Water Digital Media Series No. 9. FAO: Rome. 